\title{
Effects of Superstrate on Electromagnetically and Gap Coupled Patch Antennas
}

\author{
Ravindra Kumar Yadav $^{1}$, Jugul Kishor ${ }^{2}$ and R. L. Yadava ${ }^{3}$ \\ ${ }^{I}$ Department of ECE, JRE Group of Institutions, Greater Noida, Uttar Pradesh, India \\ ${ }^{2}$ Department ECE, I.T.S Engineering College, Greater Noida, Uttar Pradesh, India \\ ${ }^{3}$ Department of ECE, Galgotia's College of Engineering and Technology, Greater Noida, Uttar Pradesh, India
}

\begin{abstract}
In this paper the effects of water loading (termed as superstrate) on the characteristics of an electromagnetically (EM) and coupled pentagonal patch antennas operating in the ISM band have been described. The proposed antenna structures are analyzed using HFSS and the influence of the superstrate on resonant frequency, bandwidth, VSWR and radiation characteristics have also been analyzed. The obtained results also reveal that a larger bandwidth can be found in case the dielectric substrate is separated by air gap spacing. In addition, though impedance matching is little deteriorated due to loading, however the operating frequency band (BW) shifted to lower side significantly.
\end{abstract}

Index Terms: Electromagnetically coupled (EMC), electromagnetically gap coupled (EMGC), microstrip patch antenna, stacked antenna, pentagonal patch antenna.

(C) 2014 Published by MECS Publisher. Selection and/or peer review under responsibility of the Research Association of Modern Education and Computer Science

\section{Introduction}

Generally during rainy environments water may easily get accumulated over the surface of patch antennas being used in the open atmosphere. Hence exposure of patch antenna to the snow fall and buildup of snow or ice over its patch surface, or exposure to rain water and accumulation of water over its patch surface should be taken into account during the design phase. For a microstrip patch antenna which is a narrow band device exposure to such environmental conditions causing its resonant frequency getting lowered [1, 2]. Effect of dielectric superstrate on parameters such as resonant frequency, input impedance, radiation efficiency, etc. for single element microstrip patch antenna is already reported in the literature [3-6]. In past many researchers have worked on electromagnetically coupled patch antenna; First Q. Rao presented an electromagnetically

* Corresponding author.

Email address: ravipusad@gmail.com 
coupling fed broadband low profile microstrip antenna (MSA) array [7]. Radiating element is an E-shaped MSA that is fed by an electromagnetically coupled strip and covered by a low loss radome. In September 2007, Deosarkar et al. designed high gain two-layer electro-magnetically coupled patch antenna in the ISM band [8]. Latter, in March 2008, Ikeda enhanced bandwidth of a low profile microstrip antenna which is electromagnetically coupled with a Folded Inverted $L$-shaped Probe [9]. However, Lee et al. have described and characterized, an electromagnetic coupled patch antenna covered with superstrate and found that for the antenna operating in the high-gain region, the resonant input impedance increases and the $3 \mathrm{~dB}$ beam-width decreases with the dielectric thickness [10-12]. F.R. Cooray and J.S. Kot has analyzed radiation of a cylindrical-rectangular microstrip patch antenna loaded with a superstrate and an air gap between the substrate and the superstrate, using the full-wave approach as well as the electric surface current model. They presented the results in the form of normalized radiation patterns for various thicknesses of the air gap and for superstrate made of lossy dielectric material [13].

However, the effects of a water as superstrate on the centre frequency and bandwidth of electromagnetic coupled and gap coupled pentagonal patch antenna have not yet studied though both structures shows significant alteration in their performances. Therefore, authors have made an attempt to investigate and describe the effects of the water layers on the surface of the electromagnetically and gap coupled probe fed pentagonal antennas.

\section{Design of Proposed Patch Antennas}

\subsection{Design of pentagonal antenna}

In general the major advantages of a pentagonal patch antenna over the rectangular patch antenna that, it supports both linear and circular polarizations [14]. The pentagonal patch antenna provides circular polarization with only one feed where as rectangular patch antenna requires multiple feeds to get circular polarization. Hence a probe fed pentagonal antennas is chosen here for study because of its better impedance matching. The pentagonal antenna size calculations were done considering the invariance of the electrostatic energy below the pentagonal and circular patches, however maintaining their areas remain constant. Fig. 1 shows the geometry of a regular pentagonal shape, however the design specifications are given in Table 1.

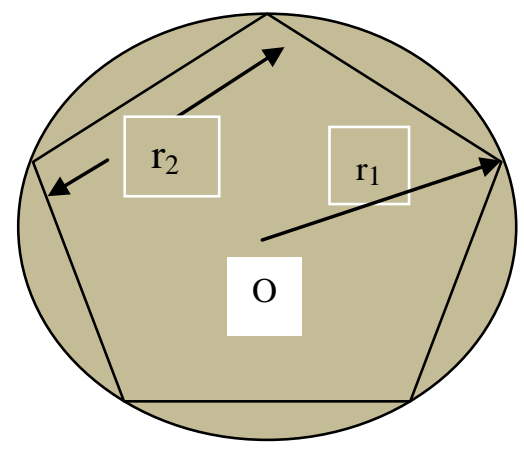

Fig. 1 Geometry of a regular pentagonal shape

The relationship between the circles $\left(r_{1}\right)$ to the side arm of the regular pentagon $\left(r_{2}\right)$ is given in equation (1).

$$
r_{2}^{2}=\frac{\pi r_{1}^{2}}{2.37}
$$


Side arm of the pentagon $\left(r_{2}\right)=1.175 r_{1}$

In the derivation of the equation (1), the pentagonal patch is assumed to be a resonant cavity with perfectly conducting side walls. Because a circular disc is the limiting case of the polygon with large number of sides, in this case number of sides are 5. The resonant frequency of the dominant as well as for the higher order modes can be calculated from the formula given below [15]:

$\mathrm{f}_{\mathrm{np}}=\frac{\mathrm{X}_{\mathrm{np}}^{\prime} \mathrm{c}}{2 \pi \mathrm{r}_{1} \sqrt{\varepsilon_{r}}}$

Where $X_{n p}^{\prime}$ are the zeros of the derivative of the Bessel function $J_{n}(x)$ of the order $n$, as is true for $T E$ mode circular waveguides, however for the lowest order modes;

$\mathrm{X}_{\mathrm{np}}^{\prime}=1.84118$

The lengths of each side of the pentagonal antenna are calculated by using equations (1) \& (2). For coaxial feed, the location of the feed point is usually selected to provide a good impedance match. The schematic of a pentagonal patch antenna is shown in Fig. 1 and design specifications are given in Table 1.

Table 1. Design parameters of the proposed antennas

\begin{tabular}{|c|c|c|}
\hline Parameters & Electromagnetically coupled antenna & $\begin{array}{l}\text { EMC gap coupled antenna (gap } \\
\text { size, } d=0.4 \mathrm{~mm})\end{array}$ \\
\hline Designed frequency $(\mathrm{GHz})$ & 2.39 & 2.41 \\
\hline Substrate 1(FR-4) & $\begin{aligned} \varepsilon_{r l}= & 4.4, \tan \delta=0.02 \\
& h_{l}=0.8 \mathrm{~mm}\end{aligned}$ & $\begin{array}{c}\varepsilon_{r l}=4.4, \tan \delta=0.02 \\
h_{l}=0.8 \mathrm{~mm}\end{array}$ \\
\hline Size of the pentagon $\left(l_{1}=l_{2}\right)$ & $28.52 \mathrm{~mm}$ & $28.52 \mathrm{~mm}$ \\
\hline Substrate 2(Plexiglas) & $\varepsilon_{r 2}=3.4, \tan \delta=0.001, h_{2}=0.8 \mathrm{~mm}$ & $\begin{array}{l}\varepsilon_{r 2}=3.4, \tan \delta=0.001, h_{2}=0.8 \\
\mathrm{~mm}\end{array}$ \\
\hline Dielectric cover(Water) & $\varepsilon_{r}=81, \tan \delta=0.0$ & $\varepsilon_{r}=81, \tan \delta=0.0$ \\
\hline Feed location & $9.0 \mathrm{~mm}$ from the centre & $9.0 \mathrm{~mm}$ from the centre \\
\hline
\end{tabular}

\subsection{Design of electromagnetically coupled patch antenna geometry}

The side views of the proposed antennas are shown in the Fig. 2 ( $a \& b)$. The lower pentagonal patch is fed by a coaxial cable and upper pentagonal patches are coupled through the fringing field.

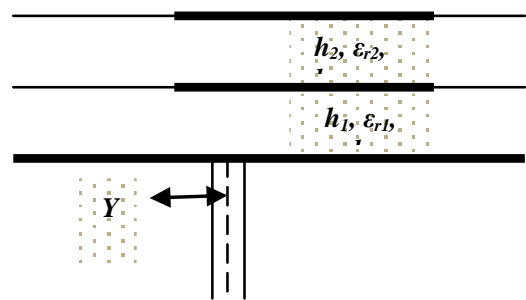

Fig. 2a Schematic diagram of electromagnetically coupled patch antenna 


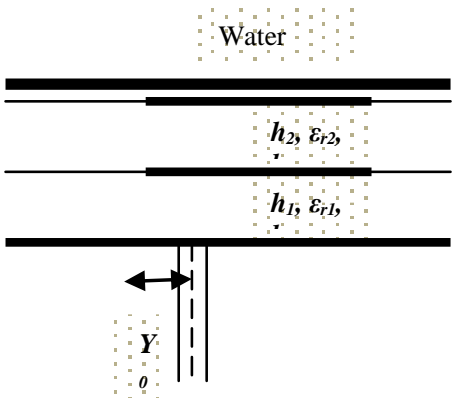

Fig. 2b Schematic diagram of electromagnetically coupled patch antenna with dielectric cover (water layer)

However the photograph of fabricated electromagnetic coupled patch antenna surface with feed line and pentagonal patch antenna are shown in Fig.3.

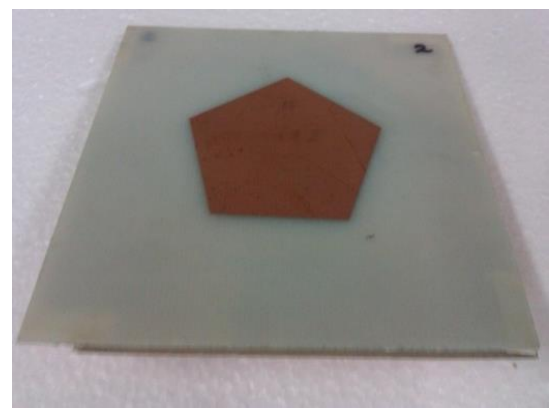

Fig. 3 Structure of electromagnetically coupled patch antenna fed with coaxial feed

\subsection{Design of electromagnetically gap coupled antenna geometry}

The geometry of the electromagnetic gap coupled patch antennas are shown in Fig. 4a \&b. The dimension of the side arm of the pentagonal patch antenna is $l_{l}$ and $l_{2}$. The thickness of the lower substrate is $h_{l}$ and the permittivity is $\varepsilon_{r 1}$ while $h_{2}$ and $\varepsilon_{r 2}$ are the substrate thickness and permittivity of the upper patch respectively. The two patches are also separated by an air gap having a distance of $d$ that can be adjusted to $0.4 \mathrm{~mm}$.

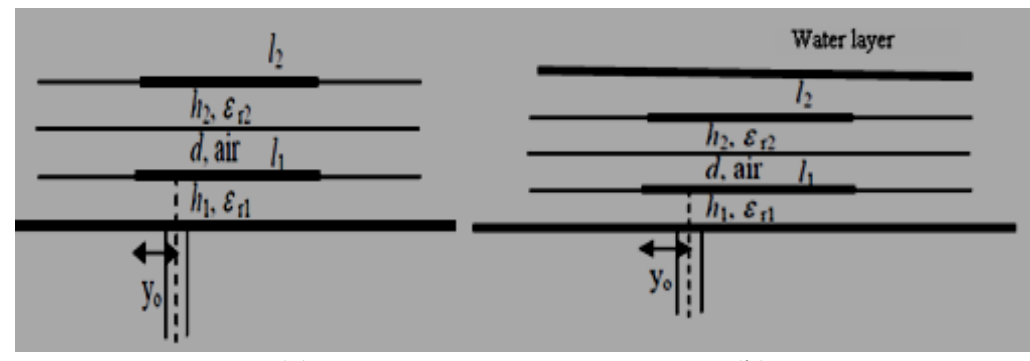

(a)

(b)

Fig. 4(a) Schematic diagram of electromagnetically gap coupled patch antenna
Fig. 4 (b) Schematic diagram of electromagnetically gap coupled patch antenna with water layer 
However the photograph of fabricated electromagnetic gap coupled patch antenna surface with feed line are shown in Fig. 5.

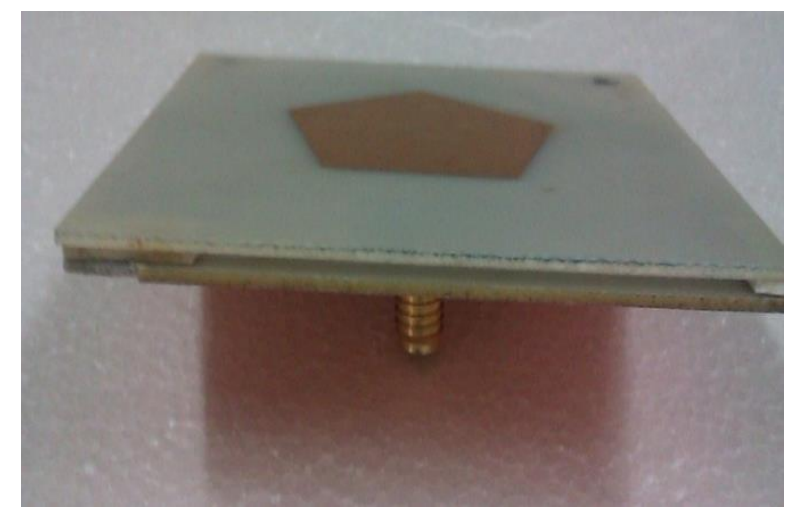

Fig. 5 Fabricated prototype of electromagnetically gap coupled patch antenna

\section{Results and Discussions}

The results of observed return loss $(\mathrm{dB})$ against frequency over the operating band of the EM coupled antenna are plotted in Fig. 6 in which $t=0$ represents an antenna without any layer while $t=0.1,0.2$ and 0.3 $\mathrm{mm}$ represents the thickness of the water layer poured on the patch surface. It can be observed from this figure that there is change in return loss over the entire frequency band due to the change in the water layer superstrate thickness $(0.1 \mathrm{~mm}$ to $0.3 \mathrm{~mm})$. However, the centre frequency and the bandwidth are also slightly changed. So, we can conclude that EM coupled antennas loaded with dielectric superstrate like water, which has very high dielectric constant, show relative change in the resonant frequency. The obtained results are also summarised in Table 2. A network analyser is used for measurements of the S-parameter and the measured results are in excellent agreements with the simulated results, which is shown in the Fig. 6 and summarized in Table 3. From the Fig. 7, it is observed that, though impedance matching is little deteriorated, the operational frequency band will be slightly changed.

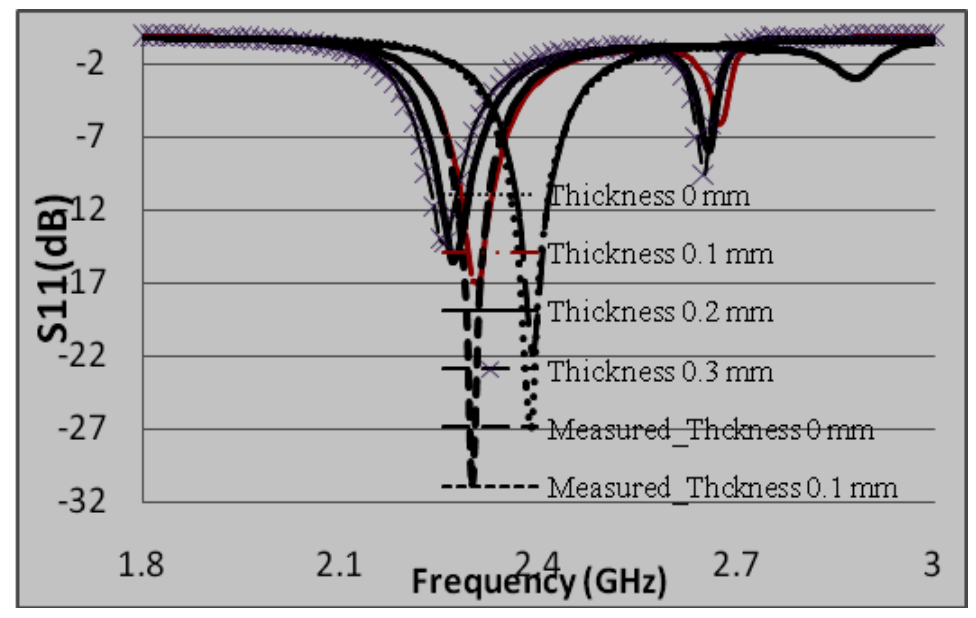

Fig. 6 Comparisons of return loss characteristics of the electromagnetically coupled patch antenna 


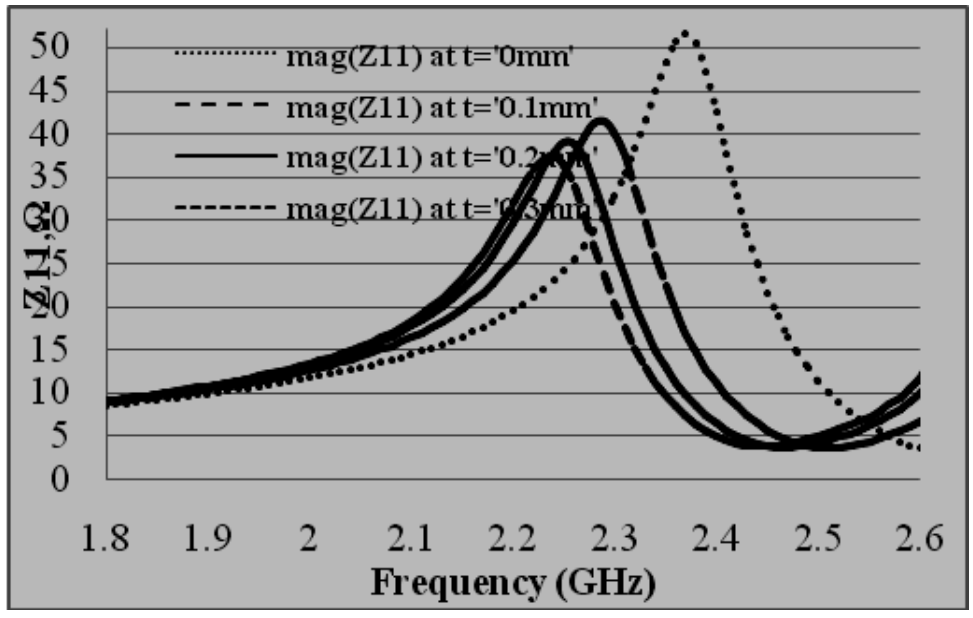

Fig. 7 Comparisons of Input Impedance EM Coupled patch antenna

Table 2 Simulated parameters of the proposed electromagnetically coupled patch antenna

\begin{tabular}{|c|c|c|c|c|}
\hline \multirow[t]{3}{*}{ Types } & \multicolumn{4}{|c|}{ Electromagnetically coupled antenna } \\
\hline & \multirow{2}{*}{$\begin{array}{c}\text { Without } \\
\text { dielectric } \\
\text { cover }\end{array}$} & \multicolumn{3}{|c|}{ With dielectric cover } \\
\hline & & $\begin{array}{c}t=0.1 \\
m m\end{array}$ & $\begin{array}{c}t=0.2 \\
\mathrm{~mm}\end{array}$ & $\begin{array}{c}t=0.3 \\
m m\end{array}$ \\
\hline Designed frequency $(\mathrm{GHz})$ & 2.39 & 2.3 & 2.27 & 2.26 \\
\hline Return loss $(\mathrm{dB})$ & -26.83 & -16.84 & -15.54 & -14.2 \\
\hline Impedance $(\Omega)$ & 47.15 & 40.06 & 37.12 & 33.9 \\
\hline VSWR & 1.095 & 1.335 & 1.401 & 1.484 \\
\hline $\mathrm{BW}(\mathrm{MHz})$ & 62.3 & 53.8 & 48.8 & 47.2 \\
\hline Gain & 0.89208 & 1.1577 & --- & --- \\
\hline Radiated Power(mW) & 19.408 & 116.14 & --- & ---- \\
\hline
\end{tabular}

Table 3 Measured parameters of the proposed electromagnetically coupled patch antenna

\begin{tabular}{|c|c|c|}
\hline \multirow[t]{2}{*}{ Types } & \multicolumn{2}{|c|}{ Electromagnetically coupled antenna } \\
\hline & $\begin{array}{c}\text { Without dielectric } \\
\text { cover }\end{array}$ & $\begin{array}{l}\text { With dielectric cover with } \\
\text { thickness } t=0.1 \mathrm{~mm}\end{array}$ \\
\hline Designed frequency $(\mathrm{GHz})$ & 2.39 & 2.3 \\
\hline Return $\operatorname{loss}(\mathrm{dB})$ & -21.90 & -30.80 \\
\hline Band Width(MHz) & 60 & 60 \\
\hline
\end{tabular}

The results of EM gap coupled antenna also reveals that return loss (dB) against frequency over the operating band of the antenna are plotted in Fig. 8 in which $t=0$ represents an antenna without any layer while $t=0.1,0.2$ and $0.3 \mathrm{~mm}$ are the thickness of the water layer poured on the patch surface. It can be observed from this figure that there is change in return loss over the entire frequency band due to the change in the water layer superstrate thickness $(0.1 \mathrm{~mm}$ to $0.3 \mathrm{~mm})$. The variation of the resonant frequency of the antenna can be explained by the variation of the effective permittivity with accumulation of the water level on the surface of the antenna. The obtained results are also summarised in Table 4 which shows that the accumulation of the water level on the surface of the patch antenna reduces the antenna parameters such as 
return loss, impedance, VSWR, etc. A network analyser from Agilent Technologies ${ }^{\mathrm{TM}}$ is used for measurements and the measured results are slightly different from simulated results, which is shown in the Fig. 8 and summarized in Table 5. The difference in the measure and simulated result are minimized by accurate measurement of water layer thickness on the patch surface and by uniform distribution of water layer on the patch surface. From the Fig. 9, it is observed that, though impedance matching is little deteriorated, the operating frequency band will be slightly changed.

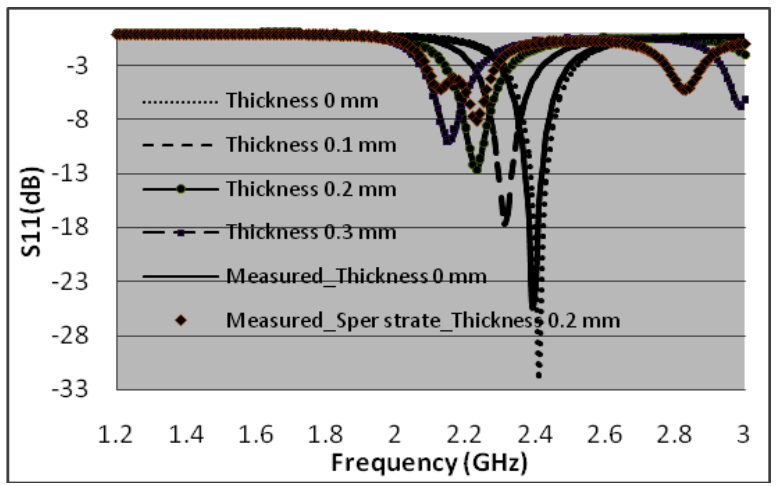

Fig. 8 Comparisons of return loss characteristics of the electromagnetically gap coupled patch antenna

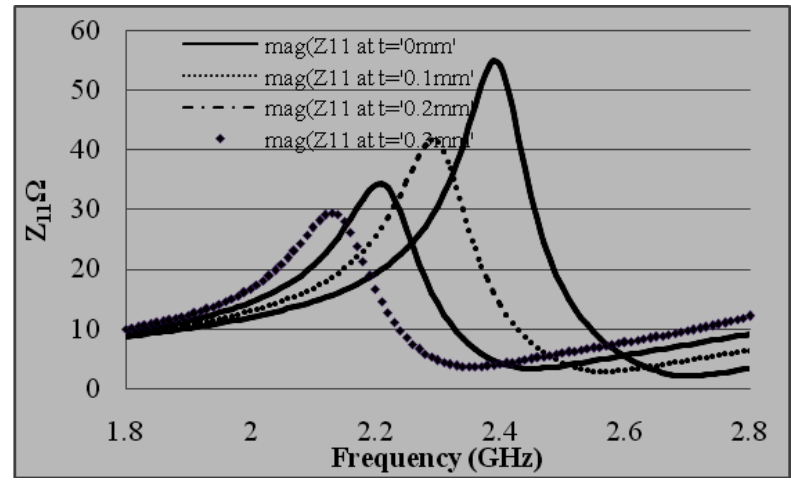

Fig. 9 Comparison of Input Impedance of electromagnetically gap coupled patch antenna

Table 4 Simulated parameters of the proposed electromagnetically gap coupled patch antenna

\begin{tabular}{ccccc}
\hline Types & \multicolumn{3}{c}{ Electromagnetically coupled antenna } \\
\cline { 2 - 5 } & Without & \multicolumn{3}{c}{ With dielectric cover } \\
\cline { 3 - 5 } & dielectric & $t=0.1$ & $t=0.2$ & $t=0.3$ \\
& cover & $m m$ & $m m$ & $m m$ \\
\hline Designed frequency $(\mathrm{GHz})$ & 2.39 & 2.3 & 2.27 & 2.26 \\
Return loss(dB) & -26.83 & -16.84 & -15.54 & -14.2 \\
Impedance $(\Omega)$ & 47.15 & 40.06 & 37.12 & 33.9 \\
VSWR & 1.095 & 1.335 & 1.401 & 1.484 \\
BW (MHz) & 62.3 & 53.8 & 48.8 & 47.2 \\
Gain & 0.89208 & 1.1577 & --- & -- \\
Radiated Power(mW) & 19.08 & 116.14 & --- & ---- \\
\hline
\end{tabular}


Table 5 Measured parameters of the proposed electromagnetically Gap coupled patch antenna

\begin{tabular}{|c|c|c|}
\hline \multirow[t]{2}{*}{ Types } & \multicolumn{2}{|c|}{ Electromagnetically Gap coupled antenna } \\
\hline & $\begin{array}{c}\text { Without } \\
\text { dielectric } \\
\text { cover }\end{array}$ & $\begin{array}{l}\text { With dielectric cover with } \\
\text { thickness } t=0.1 \mathrm{~mm}\end{array}$ \\
\hline Designed frequency $(\mathrm{GHz})$ & 2.39 & 2.23 \\
\hline Return loss $(\mathrm{dB})$ & -25.3 & -8.1 \\
\hline $\mathrm{BW}(\mathrm{MHz})$ & 70 & 0 \\
\hline
\end{tabular}

\section{Conclusion}

The behaviour of the EM couple and EM gap coupled patch antenna operating in ISM band due to the formation of a water layer superstrate on its surface is investigated. It is found that the bandwidth remains practically unaffected due to rain water accumulation on the patch surface. However, the exact value of return loss, at any particular frequency within the bandwidth, undergoes change which needs to be taken into account during system design. Analysis also shows that for $t=0.3 \mathrm{~mm}$, antenna structure totally stops responding as bandwidth is almost goes zero. So, one may conclude that accumulation of rain water on the top of the antenna surface (EM coupled and EM gap coupled) makes them prone to frequency shift as well as impedance mismatch. So effects of environmental conditions should be taken into account during the design phase of an antenna. If due care is not taken during the design phase, the system may fail to respond as per requirement.

\section{Acknowledgment}

The authors express their appreciation to Dr. B. K. Kanaujia, Professor, Department of Electronics and Communication, Ambedkar Institute of Technology, New Delhi for allows us to use HFSS simulation software and experimentations

\section{References}

[1] Inder J. Bahl, Prakash Bhartia, Stanislaw S. Stuchly, "Design of microstrip antennas covered with a dielectric layer," IEEE Transactions on antennas and propagation, vol. 30, no. 2, pp. $314-318$, March 1982.

[2] Rajeev R. Wakodkar, Bhaskar Gupta and Samik Chakraborty, "Variation of resonant frequency of a rectangular microstrip patch antenna due to accumulation of water over its surface," International conference on applications of electromagnetism and student innovation competition awards (AEM2C 2010), pp. 239 - 243,August 2010.

[3] Bhattacharyya and T. Tralman, "Effects of dielectric superstrate on patch antennas," Electronics Letters, vol. 24, no. 6, pp. 356 - 358, March 1988.

[4] J. Pribetich R. Ledee P. Kennis P. Pribetich M. Chive, "Modelling of microstrip antenna with dielectric protective layer for lossy medium," Electronics Letters, vol. 24 no. 23, pp. 1464 - 1465, Nov. 1988.

[5] O. M. Ramahi and Y. T. Lo, "Superstrate effect on the resonant frequency of microstrip antennas," Microwave and Optical Technology Letters, vol. 5, pp. 254 - 257, June 1992.

[6] A. K. Verma et. al., " Analysis of rectangular patch antenna with dielectric cover," IEICE Trans E74, 1991, pp.1270-76

[7] Q. Rao and T. A. Denidni, "Electromagnetically coupling fed broadband microstrip antennas," IEEE APS International symposium on antennas and propagation, Honolulu, Hawaii, USA, June 10-15, 2007. 
[8] S. B. Deosarkar and, A. B. Nandgaonkar, "Design of high gain two-layer electromagnetically coupled patch antenna in the ISM band," International conference on electromagnetic in advanced applications (ICEAA 07), Torino Italy, September 2007.

[9] Ikeda, "Enhanced bandwidth enhancement of a low-profile microstrip antenna electromagnetically coupled with a folded inverted L-shaped probe," Antenna technology: small antennas and novel metamaterials, International workshop, pp. $151-154,2008$.

[10] R.Q. Lee, K. F. Lee and J. Bobinchak, "Experimental study of the two-layer electromagnetically coupled rectangular patch antenna," Antennas and Propagation, IEEE Transactions, Vol.38, No. 8, pp. 1298-1302, August 1990.

[11] R.Q. Lee, K. F. Lee and J. Bobinchak, "Characteristics of a two-layer electromagnetically coupled rectangular patch antenna," Electronics Letters, Vo1.23, No.20, pp. 1070-1072, 1987.

[12] R. Q. Lee, A. J. Zaman and K. F. Lee, "Effects of dielectric superstrates on a two-layer electromagnetically coupled patch antenna," IEEE @1989, 28/5, pp. 620-623, 1989.

[13] F. R. Cooray and J. S. Kot, "Analysing radiation from a cylindrical-rectangular microstrip patch antenna loaded with a superstrate and an air gap, using the electric surface current model," CSIRO ICT Centre, P. O. Box 76, Epping, NSW 1710, Australia, 2006.

[14] M. T. Torres et al., "Pentagonal microstrip antenna equivalent to a circular microstrip antenna for GPS operation frequency," Memorias del $7^{\circ}$ Congreso Internacional de Cómputo en Optimization Software, CICOS 09. UAEM, Cuernavaca, Morelos, México. pp. 200-208, 2009.

[15] G. Kumar and K.P. Ray, "Broadband microstrip antennas," Artech House Publishers, London, 2003.

[16] Ji-jun Wang, Zhi-pan Zhu, "A Composite Heterostructure Mesh-shaped Patch Antenna Based on Left Handed Material," International Journal of Wireless and Microwave Technologies (IJWMT), Vol. 4, No. 1, pp. 10-19 January 2014.

[17] Omrane NECIBI, Abdelhak FERCHICHI, Tan-phu VUONG, Ali GHARSALLAH,"A Discussion of a 60GHz Meander Slot Antenna for an RFID TAG with Lumped Element", IJWMT, vol.4, no.2, pp.1-11, 2014.DOI: 10.5815/ijwmt.2014.02.01.

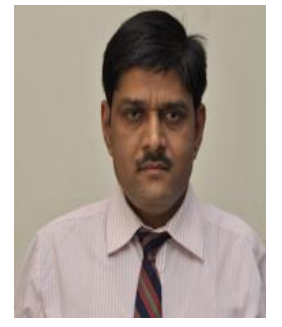

Dr. Ravindra Kumar Yadav is an Professor in the Department of Electronics \& Communication Engineering at JRE group of Institutions, Greater Noida, U.P. Technical University Lucknow, Uttar Pradesh. He is B.E from B. N. College of Engineering, Pusad, Maharastra and M.E. from M.S. University, Baroda, Gujrat. And $\mathrm{PhD}$ in the field of antenna. He has 17 years of teaching experience in the field of microwaves and EM waves and also published the several papers to his credit in international/national journals, conferences and symposiums on antennas and fractal antennas. He has guided several B. Tech and M. Tech project. He is also the member of IEEE

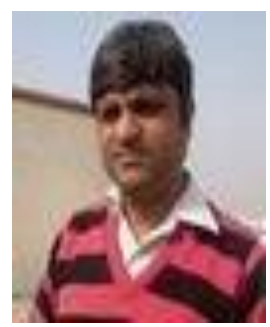

JUGUL KISHOR received his $M$. Tech degree in Microwave Electronics from University of Delhi South Campus, New Delhi, India, in year 2008 and B.Tech degree from Kamla Nehru Institute of Technology, Sultanpur, India He is currently working as Assistant Professor with the Department of Electronics and Communication Engineering, ITS Engineering College, Greater Noida G. B Nagar, U. P., India. His recent research interest activities have focused on the novel antennas Design, Characterization and application of periodic structure and microwave wireless communication. He has done various projects in SAMEER-CEM; Chennai under Antenna division. He has authored various research papers in international and National Conferences proceeding paper and guided one M. Tech Projects. 


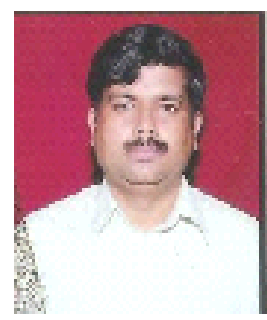

Dr. R.L.Yadava, is Professor in the department of ECE, Galgotias College of Engg and Technology, Gr. Noida, U.P. During his doctoral work he was associated with R \& D project funded by DST, Govt. of India. After receiving Ph.D. degree, he joined VIT University, Vellore T.N, in 2001 and served as Head of Microwave Division, Coordinator R\& D and Co-ordinator (UG) of Electrical Sciences. He has also been coordinator of M.Tech programme of U.P.Technical University, 2007-08. During his service at VIT, he was deputed as visiting faculty to KIGALI UNIVERSITY, KIGALI Center Africa. Dr. Yadava has organized several guest lectures, short-term training programmes and conferences in the field of Microwaves and Antennas. His research areas includes: Waveguides, Microwaves and Microstrip Antennas. He has guided several B.Tech and M.Tech projects and ten $\mathrm{Ph} . \mathrm{Ds}$ are in progress under his supervision. He has 35 publications in International/ National Journals, Conferences and Symposiums. He is associate editor of Journal of Information, Intelligence and Knowledge, USA and also the member of ISTE, SEMCE (I) and IEEE.

How to cite this paper: Ravindra Kumar Yadav, Jugul Kishor, R. L. Yadava,"Effects of Superstrate on Electromagnetically and Gap Coupled Patch Antennas", IJWMT, vol.4, no.3, pp.26-35, 2014.DOI: 10.5815/ijwmt.2014.03.03 